\title{
UMA NEURO-WELTANSCHAUUNG? FISICALISMO E SUBJETIVIDADE NA DIVULGAÇÃO DE DOENÇAS E MEDICAMENTOS DO CÉREBRO'
}

Rogerio Lopes Azize

É inegável o lugar de destaque que o cérebro ocupa no imaginário contemporâneo ocidental. Parece-me ser o órgão do corpo humano a respeito do qual há mais excitação na mídia e no discurso leigo, talvez devido à profusão de notícias e às representações que têm o cérebro e as doenças que o podem acometer como centro. ${ }^{1}$ Especialmente entre as classes médias e altas urbanas, ${ }^{2}$ com maior acesso aos serviços de saúde de ponta em termos tecnológicos, vemos reproduzida a vertente neurológica e psiquiátrica — com a primeira tendendo a englobar a segunda - do fisicalismo reducionista que caracteriza a biomedicina ocidental. Acredita-se estar no cérebro o lugar da mente, da consciência, da memória, das doenças do mundo psi; a idéia de que o cérebro é condição suficiente para a existência do que entendemos como "indivíduo" parece ter entrado para o mundo dos fatos científicos, que repetimos cotidianamente quando falamos sobre os estados de saúde/doença mental.

Na multiplicação de discursos sobre o cérebro e as doenças a ele associadas, alguns temas aparecem com maior preeminência, caso da depressão e da ansiedade; estas doenças, nos termos da leitura biomédica contemporânea que se faz delas, surgem com uma roupagem que pouco tem em comum com as explicações de ordem psicanalítica ou com a leitura do sistema humoral (Cairus 1999). Mostrarei que, com diferentes vocabulários, autores remetem ao surgimento de um "sujeito cerebral" (Ehrenberg 2004; Vidal 2005), figura que ganharia força no final do século XX, acompanhada de uma profusão de discursos sobre neurotransmissores e sua conexão com a saúde mental, tecnologias de visualização do cérebro e um borrar das fronteiras entre cérebro, o órgão, e idéias menos materializáveis, como a de mente.

A medicalização de doenças como "depressão" e "ansiedade" tem suscitado um debate interdisciplinar que tenta dar conta das conexões entre o espraiamento desse fenômeno e os valores centrais que animam a 
cultura ocidental. Os transtornos de humor e de ansiedade têm sido motivo de discussões que envolvem as ciências sociais, a filosofia e a medicina, em virtude das transformações que ocorreram após o lançamento do Prozac, o mais conhecido dos inibidores seletivos da recaptação de serotonina ISRSs: ${ }^{3}$ o número de diagnósticos dessas doenças aumentou em progressão geométrica, a ponto de a depressão ser candidata à "doença do século XXI"; livros e artigos propõem-se a discutir se um grande percentual dos usuários está realmente clinicamente depressivo ou ansioso, ou se estaríamos fazendo uso dessa tecnologia enquanto enhancement, melhoria de si, não necessariamente tratando estados patológicos.

Um agente importante no processo de construção social de doenças associadas ao sistema nervoso são os laboratórios farmacêuticos. Os mecanismos publicitários através dos quais os laboratórios divulgam os seus produtos muitas vezes se confundem com a divulgação das doenças elas mesmas, em campanhas informativas de disease awareness, por vezes veiculadas sob o rótulo "informativos publicitários", termo que fica na divisa entre uma peça publicitária e outra que divulga informações de utilidade pública. Discuto com qual formato emerge uma noção de "pessoa" a partir da publicidade dos laboratórios farmacêuticos voltada para a divulgação da "depressão" para o público leigo, e de antidepressivos, ansiolíticos e tranqüilizantes para o pessoal médico. Nessas peças, fisicalismo e subjetividade misturam-se em mensagens cujo conteúdo se concentra na moderna "linguagem da serotonina" ou "do cérebro", mas deixam transparecer o caráter físico-moral das doenças ao fazerem uso de valores que estão no cerne da concepção moderna de indivíduo no Ocidente, como "autonomia", "liberdade" e "natureza".

\section{O cérebro no centro das atenções}

O cérebro tem ocupado capas de revista de grande circulação, publicações de divulgação científica voltadas para leigos, publicidade dos laboratórios farmacêuticos que produzem remédios psiquiátricos e almoços em família. Basta uma visita a uma banca de revistas para confirmar o que é dito aqui: já há publicações em português que têm no cérebro o seu assunto central (como a revista Viver mente e cérebro), mas ele pode também ser coadjuvante em reportagens sobre temas tão variados quanto café, doenças, paternidade, exercícios físicos, sono irresistível que invade sem avisar ou insônia, e ainda sentimentos como o ciúme, a felicidade ou a timidez. ${ }^{4}$

O cérebro surge como um déspota que domina a nossa subjetividade, um órgão imperador que rege estados de humor e define a nossa identidade. 
Dizendo melhor, noções como a de mente ou a de subjetividade passam para segundo plano, enquanto ganha força um cérebro que gera conseqüências em um corpo. Falamos da química cerebral com certa naturalidade, comentamos os efeitos dos neurotransmissores como se eles fossem nossos velhos conhecidos; em suma, falamos uma espécie de "linguagem da serotonina", que parece ser hoje hegemônica entre o público leigo, da mesma forma que um dia já falamos uma "linguagem psicanalítica". Da insônia à inteligência, da "depressão" à "ansiedade" em suas várias manifestações, novas e velhas questões têm etiologia, cura ou debate ligados ao cérebro e aos neurotransmissores. Para Healy, o marketing dos laboratórios farmacêuticos tem uma influência central nessa mudança de perspectiva:

Sob a influência do marketing dos ISRS, esta psicobalela (psycobabble) está rapidamente sendo substituída por uma biobalela (biobabble), que fala sobre níveis baixos de serotonina e coisas no gênero, de uma forma divorciada de qualquer quadro de referência científica (Healy 2004:233).

Novas pesquisas na área de neurociência são acompanhadas de perto pela mídia e têm apresentado uma interseção com questões éticas, legais e sociais que pedem por um debate interdisciplinar. E essas questões tendem a se multiplicar com o possível surgimento de novas tecnologias de neuroimagem (Racine et alii 2006); exemplo disso é a possibilidade de que brain-scans sejam utilizados em processos jurídicos como argumento para discutir se um réu é ou não imputável (como mostra Cornwell 2004).

Fala-se das pesquisas atuais em neurociência como um prelúdio de grandes revoluções futuras em termos de como entendemos nosso corpo, nossa subjetividade, nossa "natureza". Uma das vozes mais otimistas nesse campo, Nancy Andreasen (2001), afirma ser objetivo de longo prazo encontrar a "penicilina da doença mental" — chegado esse momento, a esquizofrenia poderia ser tratada da mesma maneira que uma doença infecciosa, o que significa que saberíamos claramente suas causas e formas de tratamento; saberíamos um dia que as modificações de humor que atravessam o nosso cotidiano são fruto na verdade da química cerebral. ${ }^{5}$

Enquanto as vozes mais otimistas cantam um futuro no qual veremos o cérebro acontecendo, alguns autores têm se perguntado a respeito do formato desse porvir. Ao refletir sobre as possibilidades do projeto Genoma, Rabinow (1999:137) lança uma questão etnográfica, à qual quero fazer eco aqui: "como irão mudar nossas práticas e éticas sociais à medida que este projeto avance?". Uma de suas hipóteses é a de que com o esquadrinhamento do genoma 
[...] haverá a formação de novas identidades e práticas individuais e grupais, surgidas destas novas verdades. Haverá grupos portadores de neurofibromatose que irão se encontrar para partilhar suas experiências, fazer lobby em torno de questões ligadas a sua doença, educar seus filhos, refazer seus ambientes familiares etc. É isso que entendo por biossociabilidade (ibidem:147).

A idéia de Rabinow também vale para um maior esquadrinhamento do cérebro: ainda que no Brasil a prática de montar associações seja menos difundida que nos EUA, a previsão de Rabinow já pode ser percebida por aqui, no caso de doenças cuja tese etiológica encontra-se fortemente ligada a um mau funcionamento do cérebro (ver Dumit 2004). Uma visita rápida ao Orkut, sítio de relacionamento na Internet, mostra um grande número de grupos ligados à "depressão" e à "ansiedade" ou aos medicamentos usados para o seu tratamento. ${ }^{6}$

As novas tecnologias de medicalização e visualização do cérebro vêm suscitando questionamentos de diferentes ordens sobre as suas possíveis conseqüências. Uma vez criada uma pílula que melhorasse a nossa capacidade de memorização, um vestibulando poderia ter acesso a ela, ganhando vantagem sobre um concorrente? Quais os limites entre estados normais e patológicos quando se trata de medicalizar estados depressivos e de ansiedade? A relação entre o cérebro e a consciência seria de causalidade - neste caso, a segunda seria efeito do primeiro - ou de solidariedade, como se apresentam as teses não-reducionistas que sabem que a consciência não pode prescindir do cérebro, mas não afirmam que a primeira se reduz ao segundo? Estaríamos rumando para uma medicalização da "subjetividade", ou da "vida" ela mesma, com argumentos hoje difíceis de refutar — visto ocuparem o lugar de palavras mágicas do nosso tempo - como a busca por mais "qualidade de vida"?

Ao que parece, o dualismo alma-mente/corpo, em que se baseia o pensamento ocidental desde Descartes, é colocado em xeque quando a alma e a consciência passam a ser vistas como um reflexo daquilo que acontece no cérebro; nos termos de um reducionismo radical, falaríamos em "alma" ou "consciência" como entidades não-materiais simplesmente porque não conhecemos ainda as causas últimas daquilo que consideramos o nosso "eu": a atividade cerebral. ${ }^{8}$

O fisicalismo cerebral e a "linguagem da serotonina" parecem estar assentados sobre uma tese que não está cientificamente estabilizada, e por essa razão a ampla medicalização de doenças cujas causas estariam ligadas ao mau funcionamento de neurotransmissores sofre críticas mesmo entre profissionais da saúde (como em Healy 2004). Nossos "males do cérebro" 
são explicados hoje por uma tese que parece prescindir de marcadores biológicos, visto que não há exame sólido para comprová-la: um problema de recaptura da serotonina e/ou da noradrenalina entre as células nervosas do cérebro, de forma que estes neurotransmissores não cumprem o seu papel ideal: funcionar como uma espécie de ponte entre os neurônios. Mas essa "não-estabilização" não significa que a tese não produza efeitos contundentes em uma cultura que tem nos discursos e nos fatos técnico-científicos um lugar de verdade, de mobilização do público leigo. Do nosso ponto de vista, mesmo a "estabilização" de uma teoria não a coloca fora do campo de reflexão da antropologia, já que nos interessa o processo através do qual essa "verdade científica" está sendo construída (Latour e Woolgar 1997; Latour 2000). Acredito que as peças publicitárias dos laboratórios farmacêuticos que divulgam as "doenças" entre o público leigo e entre os profissionais de medicina são parte desse processo.

A emergência de um "sujeito cerebral" pode ser vista como mais uma manifestação do fisicalismo reducionista que toma conta dos discursos médicos contemporâneos; mas cabe notar que se trata de uma de suas manifestações mais interessantes, visto que toca em pontos ligados à subjetividade, à construção do sujeito e à saúde mental — esta sendo um local ambíguo no que diz respeito às doenças, visto que ali se encontram de forma mais clara os discursos físicos, morais e mentais sobre saúde/doença (Duarte 2003).

Essa visão de mundo que cola o indivíduo ao seu cérebro coloca um desafio à antropologia: refletir sobre a noção de "pessoa" que atravessa tal idéia. ${ }^{9} \mathrm{~A}$ centralidade do cérebro na cultura contemporânea despertou a atenção de autores cujos trabalhos discuto a seguir, mas considero que a amplitude da bibliografia não permite esgotar o tema. Em outro registro, analisar peças publicitárias de laboratórios farmacêuticos lança luz sobre o processo de construção social da "depressão", devido ao acesso que a indústria tem aos médicos ${ }_{1}^{10}$ e também pelo acesso aos possíveis consumidores, via mecanismos publicitários que divulgam não somente novos medicamentos, mas "doenças". Nessas peças publicitárias, uma visão fisicalista dos "transtornos do cérebro" convive com um corpo de representações que nos remete ao caráter moral destas mesmas doenças. Tento mostrar que tanto no debate teórico de autores preocupados com a questão da medicalização das doenças psi, quanto na publicidade dos laboratórios fica expressa uma tensão entre pares, como autonomia e liberdade versus determinismo químico, natureza versus intervenções químicas no corpo, pares dos quais fazem parte algumas das categorias centrais para a constituição do sujeito ocidental. 


\section{Os teóricos de um sujeito cerebral}

A visão fisicalista, mais especificamente cerebral, de doenças como a "depressão" e a "ansiedade" vem sendo discutida por autores como Bezerra Jr. (2000); ele lembra que a psiquiatria, desde o seu nascimento, tem incorporado em sua prática os dualismos da cultura ocidental, de forma que a experiência humana é entendida como se comportasse uma dupla dimensão, por um lado, física/orgânica, por outro, moral/psicológica. Apesar dos conflitos teóricos entre perspectivas clínicas diferentes, a aceitação do dualismo permitia "um reconhecimento recíproco das partes divergentes como participantes de um mesmo campo complexo" (Bezerra Jr. 2000:159).

Para o autor, o paradigma atual biomédico sobre as doenças do sistema nervoso perderia de vista essa perspectiva dualista. O quadro do momento parece ser o de um novo avanço das teses fisicalistas, "ofensiva que ultrapassa os limites do campo psiquiátrico e invade progressivamente a cultura, o imaginário social e a linguagem do dia-a-dia" (ibidem:160). Certa linguagem neurológica que situa estas doenças como se acontecessem no cérebro, geradas por um desequilíbrio químico, estaria passando por um processo de vulgarização. O que estaria em jogo seria a dissolução do paradigma dualista, "com a adoção de uma perspectiva monista caracterizada por um fisicalismo de corte especial, francamente reducionista" (ibidem:161).

Bezerra Jr. não é o único a comentar esse enfoque do fisicalismo radical no contemporâneo, naquilo que diz respeito a questões ligadas ao cérebro. Em um texto chamado "Le sujet cérébral", Ehrenberg (2004) também discute as fronteiras entre a psiquiatria e a neurologia a partir de uma mudança de paradigma, na transição do século XX para o século XXI, caracterizada pela assunção de uma base materialista para o espírito, que entende o cérebro como um fundamento do espírito. Ele percebe na neurociência contemporânea um programa fraco e um programa forte. O fraco quer progredir no que diz respeito às pesquisas envolvendo Parkinson ou Alzheimer, doenças tidas como de fundo neurológico; o programa forte quer fazer coincidir o conhecimento de si com o conhecimento do cérebro, tratar psicopatologias em termos de neuropatologias, que poderiam ser abordadas como uma espécie única de doença e, em mais longo termo, agir eficazmente sobre a nossa "máquina cerebral" para aumentar a nossa capacidade de ação e decisão. Trata-se de um momento em que poderíamos pensar na fusão entre neurologia e psiquiatria. Teríamos aqui o que ele chama de uma biologia do espírito ou do indivíduo, ou uma "neurobiologia da personalidade" (ibidem:132).

No contexto do que ele chama de "programa forte" das neurociências, estariam no mesmo lugar a esquizofrenia, a "depressão" e o Alzheimer. Em 
outras palavras, em algum tempo estaríamos tratando patologias psiquiátricas como problemas neurológicos. Num quadro assim, Ehrenberg afirma que o cérebro "não pode ser mais considerado hoje somente como um objeto científico e médico, ele foi promovido também a ator social", podendo tornar-se um "objeto de identificação, um meio de se reconhecer como agente social" (ibidem:133).

Afinal, nossas dificuldades são psicológicas ou neuroquímicas? Há um contexto que permite pensar o cérebro como indivíduo, ou pensar a si mesmo como cérebro doente ou sadio. Mas que contexto social seria este, como explicar as razões sociais do sucesso popular das neurociências? Para Ehrenberg, a resposta não estaria simplesmente em um avanço técnico da visualização ou da medicalização do cérebro; a sua tese é a de que "uma representação de si como cérebro doente" constitui uma "referência semântica apropriada", um consolo para aqueles que têm "dificuldades de encarar o mundo de decisão e ação que se edificou sobre as ruínas da sociedade da disciplina" (ibidem:147).

Assim como Ehrenberg, Nikolas Rose $(2003,2007)$ também relaciona a alta incidência de "depressão" e "ansiedade" à concepção contemporânea de "pessoa", que envolveria a obrigação de "liberdade", "responsabilidade" e "escolha". Em face da norma que incita à "ação", à "escolha", à "auto-realização" e ao "melhoramento de si" (self-improvement), diferenças seriam julgadas como patologias. Rose propõe o termo neurochemical self, relacionando o contexto cultural no qual emerge esse self ao aparecimento de "doenças", como "depressão" e "transtorno de ansiedade generalizada", ao desenvolvimento de drogas como Prozac e Paxil, ao marketing dessas marcas e às estratégias das indústrias farmacêuticas, sem construir uma hierarquia de causalidade entre estes itens.

Ele se apropria do tema em seu caráter complexo, afirmando que a idéia de um neurochemical self não apenas muda nossa forma de refletir sobre transtornos de pensamento, humor ou conduta, mas tem um enorme impacto no nosso cotidiano, do local de trabalho à escola, da família à prisão, do quarto às quadras esportivas. Essa forma de ver as condutas do dia-a-dia em termos da sua neuroquímica "é apenas um elemento de uma mutação mais ampla na qual nós, no Ocidente, mais especialmente nos EUA, passamos a entender nossas mentes e selves em termos de nossos cérebros e corpos" (Rose 2003:46).

Para Rose, uma mudança essencial está no âmago da incidência de "depressão" no Ocidente: na segunda metade do século XX, fomos perdendo um sentido psicológico do self e passamos a desenvolver o que ele chama de uma "individualidade somática": 
Por individualidade somática, refiro-me à tendência de definir aspectoschave da individualidade de cada um em termos corporais, o que significa pensar a si mesmo como "embodied", e entender esse corpo nos termos da biomedicina contemporânea. Ser um indivíduo somático, nesse sentido, é codificar as suas expectativas e medos nos termos desse corpo biomédico, e tentar reformar-se, curar-se ou melhorar-se atuando naquele corpo (Rose 2003:54).

O espectro ao qual Rose se refere inclui dar nova forma ao corpo visível dietas, exercícios, tatuagens - e também entender os desejos e os problemas em relação ao funcionamento interno do corpo orgânico, tendo o cérebro um papel crucial enquanto fonte de transtornos e local de tratamento.

O que Rose parece propor é uma versão modificada da idéia de biopoder: a nova geração de drogas psiquiátricas carrega consigo menos uma idéia de "cura" e mais uma idéia de gestão do risco (risk management), na qual os indivíduos devem estar engajados através de atos de escolha. Esse neurochemical self do qual Rose fala transita em um universo em que os limites entre doença e vicissitudes da vida são tão pouco claros quanto os limites entre cura, normatização e enhancement (ibidem:58-9).

Como vimos, a dissolução do paradigma dualista e expressões como "sujeito cerebral", "self neuroquímico", "neurobiologia da personalidade" são algumas das idéias e das formas através das quais os autores estão se referindo a uma conexão entre o papel do cérebro e a maneira como entendemos a idéia de indivíduo ou o conceito de "pessoa". Outros autores têm lidado com certas práticas de intervenção farmacológica bastante atuais quanto à sua tensão físico/moral, como denota a expressão "psicofarmacologia cosmética" (Kramer 1994). O termo remete à possibilidade de que drogas psicoativas estejam sendo utilizadas não para tratar doenças, mas para melhorar o bem-estar psíquico, uma prática que ele acredita fazer as pessoas transitarem entre estados normais, e não entre estados normais e patológicos. Vejamos como este debate diz respeito a questões de caráter moral, mais do que de caráter fisiológico.

\section{Debates morais em torno da neuro-psico-farmacologia}

Antes de mais nada, é necessário deixar claro no que consiste a idéia de enhancement e quais os termos do debate que esse conceito tem suscitado, para depois mostrar a relação entre este assunto e a análise que será feita de peças publicitárias da indústria farmacêutica. 
Não encontrei uma tradução da palavra para o português na literatura de ciências humanas, talvez porque ainda não haja trabalhos com uma reflexão específica sobre o tema. O dicionário (Lello) oferece os termos aumento, acrescentamento, elevação, engrandecimento, tendo o sentido de um "algo a mais" em relação a uma base inicial. Juengst (1998:29) oferece a seguinte definição: "O termo enhancement é geralmente utilizado em bioética para caracterizar intervenções destinadas a melhorar a forma ou o funcionamento humano além do que é necessário para sustentar ou restaurar a boa saúde". Neste sentido, talvez o termo "melhoramento" seja uma tradução adequada. A idéia de enhancement é bastante espinhosa porque se trata de um conceito moral - ou físico-moral, se lembrarmos que a expressão pode designar intervenções com alguma conseqüência direta na vivência corporal; o limite entre uma intervenção médica caracterizada como "tratamento" e uma outra qualificada como enhancement é muito tênue, envolvendo um debate sobre quais seriam os limites da medicina e quais estados físicos devem ou não ser alvo de intervenções medicamentosas, cirúrgicas etc. (Parens 1998). ${ }^{11}$

O amplo uso que vem sendo feito de antidepressivos e ansiolíticos fez com que o debate sobre enhancement cruzasse com certo uso contemporâneo da psicofarmacologia, especialmente desde o lançamento do Prozac. Uma pergunta importante é se a ampliação do uso destas classes de medicamentos não estaria fazendo com que não só fossem tratadas "doenças" clinicamente diagnosticadas como a "depressão" e a "ansiedade", mas também houvesse um uso que provocaria nas pessoas a passagem de um estado normal para outro. ${ }^{12}$

Para fins deste artigo, interessa-nos particularmente o debate moral que o termo suscita. Expressões como "autenticidade", "liberdade", "uniqueness", "livre-arbítrio" e seus contrários são colocadas sobre a mesa quando está em pauta o uso de psicofármacos. Da forma como vemos, esses pares de oposição são, de alguma forma (em termos de seus valores ideológicos), incorporados aos discursos da publicidade feita pela indústria farmacêutica, como veremos no próximo tópico.

O debate que tem sido suscitado sobre o uso de antidepressivos reflete questões mais amplas da cultura ocidental. Elliott (2004) retrata bem essa questão ao afirmar que a vida moderna nos impulsionaria em duas direções morais distintas. Uma delas diz respeito à herança de uma tradição moral ${ }^{13}$ que valoriza a noção de autenticidade; conceitos como integridade moral versus traição de si (self-betrayal), sinceridade ou duplicidade, being true to yourself só fariam sentido porque acreditamos possuir selves individuais, que apresentam unidade e integridade no decorrer do tempo e, centralmente, que nós devemos ter um comprometimento moral com a manutenção dessa 
unidade. Uma ética da autenticidade nos ensina que uma vida plena de significado passa pela descoberta e pela busca de valores, ideais e talentos que seriam peculiares a cada um de nós enquanto indivíduos. Mas esse vocabulário moral surgiria em um pano de fundo que valoriza a adoção de uma identidade flexível e adaptável, contra a idéia de que temos que nos reinventar a cada momento, transitar por diferentes identidades para que tenhamos uma vida rica em experiências.

Este é um debate, creio, paralelo ao desenvolvido por Sennett (2005) sobre as mudanças no mundo do trabalho: se, no paradigma atual do mundo do trabalho, pede-se fluidez e um espírito adaptável, por vezes esses valores vão de encontro à identidade desejada em termos da vida íntima; a identidade profissional "leve", com vínculos de caráter transitório, não existe sem conseqüências para a vida íntima, se lembrarmos da centralidade da categoria trabalho para nós. A questão, conforme aponta Sennett, é como criar um discurso que coloque ordem na ambigüidade entre os valores da leveza e da mobilidade social, por um lado, e a valorização das raízes, da autenticidade, por outro.

O debate moral sobre o Prozac e outros antidepressivos e ansiolíticos carregaria essa mesma tensão e ambivalência sobre a idéia de autenticidade. Trata-se da liberdade de se reinventar a cada momento - e o uso de psicofármacos seria uma das formas de atingir esse fim - ou estaríamos sendo fechados em uma espécie de jaula química, que mantém um "verdadeiro eu" encarcerado enquanto o medicamento faz efeito? Para alguns, o enhancement psicofarmacológico é a ponta de um admirável mundo novo, com medicamentos como o Prozac sendo comparados ao Soma. ${ }^{14}$ Para outros, a resistência moral ao uso dos psicofármacos caracterizado como enhancement é exatamente isto: uma questão moral.

DeGrazia (2004), por exemplo, questiona a idéia de que o uso de psicofármacos para fins de enhancement ou self-improvement seja um ataque à autenticidade do self. Para ele, os argumentos contrários ao enhancement trazem embutidos a concepção de que o self é um dado, uma realidade preexistente; essa visão negligenciaria aquilo que DeGrazia vai chamar de as possibilidades de criação de si (self-creation). A chave do seu argumento está na seguinte pergunta: por que alguns tipos de self-improvement são considerados autênticos, como exercícios físicos ou educação, e outros seriam considerados artificiais e não-autênticos, como o uso de antidepressivos para fins de enhancement?

A idéia de self-creation, segundo DeGrazia, está estreitamente vinculada ao livre-arbítrio, fazer escolhas para si mesmo, modificar a sua identidade conforme a valoração de determinados traços que portamos, e dos quais 
podemos, ou não, querer nos livrar. Os críticos diriam que o Prozac configura um artifício, um atalho não-natural ou artificial rumo ao self-improvement; a psicoterapia, em contrapartida, seria considerada mais "natural", por carregar uma implicação mais radical do indivíduo, e consistir em um processo autêntico de transformação.

Tornar-se outro por meio de psicofármacos - esses textos parecem perguntar - desestabiliza as políticas dominantes da subjetividade, constituindo uma prática de "criação de si", ou estamos aqui justamente no pólo oposto, o da conformação, da sujeição da subjetividade e do corpo aos mecanismos de biopoder via intervenção química? ${ }^{15}$ Ora, essa pergunta atravessa os textos, com os quais tive contato, a respeito das tecnologias de enhancement. Sem dúvida, um dos aspectos fortes do debate acadêmico sobre a medicalização de doenças como "depressão" e "ansiedade" enfoca a oposição entre determinismo químico e agência moral.

Os paradoxos dos possíveis usos de novas tecnologias biomédicas para fins de enhancement, de "melhoria de si", os limites entre estados patológicos e saudáveis e a fronteira que deve limitar as intervenções médicas são preocupações destes autores que ainda não foram resolvidas. Parece-me que este debate não está próximo do fim, em primeiro lugar, por envolver questões morais de difícil resolução que atravessam as nossas definições de humano, de ciborgue, de pós-humano, de identidade, de "pessoa"; e também porque o surgimento de novas técnicas de intervenção, além do possível avanço das tecnologias existentes, trará novas perguntas que devem se multiplicar no século XXI. Alguns dos conceitos utilizados na tentativa de refletir sobre o processo complexo de medicalização de doenças como "depressão" e "ansiedade" marcam paradoxos que são expressos também na publicidade de medicamentos para o sistema nervoso, como veremos no tópico a seguir.

\section{Fisicalismo e subjetividade na publicidade da indústria farmacêutica}

Em que sentido o debate a respeito da idéia de enhancement pode nos ser útil aqui, quando nos propomos a entender as campanhas de divulgação de doenças e os medicamentos ligados ao sistema nervoso veiculados pelos laboratórios farmacêuticos? Algumas vozes têm se levantado em um tom denunciatório para apontar que muitas das estratégias de marketing dos laboratórios consistem justamente em borrar os limites entre enhancement e tratamento, com o objetivo de ampliar o espectro de estados diagnosti- 
cáveis como patológicos e, assim, ampliar o mercado consumidor de medicamentos. ${ }^{16}$ Essas peças de publicidade, em seu texto ou nas imagens que divulgam, atualizam algumas das tensões tratadas no tópico anterior, como entre enhancement e "criação de si" — maquiagem química ou uma espécie de autodescoberta por meio da química - além de falarem sobre valores como "autenticidade", "autonomia", "liberdade" e "escolha".

Já vimos que alguns dos valores mais caros à constituição do sujeito moderno - autonomia, liberdade, singularidade — são objeto de atenção dos autores interessados nos impactos físicos e morais da medicalização do cérebro, especialmente no que toca ao período posterior à explosão dos ISRSs, produtos da mesma linha do Prozac. Se alguns vêem a medicalização do cotidiano como uma forma de maquiagem psíquica, outros acreditam que não haveria nada de moralmente errado com as tecnologias farmacológicas de melhoramento de si (enhancement) que, em essência, em nada se diferenciam de processos que envolveriam um esforço de si, como a psicanálise.

A tensão entre esses valores está expressa em um objeto etnográfico peculiar: peças publicitárias utilizadas pelos laboratórios farmacêuticos para divulgar doenças e medicamentos ligados ao sistema nervoso, algumas delas voltadas para o público leigo, outras para os profissionais da biomedicina. São folhetos que podem ser encontrados nas salas de espera de consultórios médicos e informam sobre as características da "depressão", seus sintomas, causas e tratamento adequado; material de sítios na Internet voltados para a divulgação dos sintomas associados aos medicamentos; anúncios de jornal assinados por laboratórios, chamados "informativos publicitários", que divulgam o perfil da doença, sua especificidade em termos de diagnóstico e tratamento e o esforço do laboratório em criar novas tecnologias de tratamento; peças de divulgação voltadas para o público especializado, como CDs promocionais; e ainda anúncios em revistas como a Diálogo Médico, publicada pelo laboratório Roche e com distribuição gratuita e exclusiva para a classe médica.

Na capa de um folheto do laboratório Lilly, fabricante dos antidepressivos Prozac e Cymbalta, voltado para o público leigo e disponível na sala de espera do consultório de um psiquiatra, há a chamada "Você sabe reconhecer os sintomas da depressão?". O texto do folder apresenta a etiologia da "doença" da seguinte forma:

Duas substâncias químicas vitais são responsáveis pela depressão. Muitos especialistas acreditam que a depressão é causada por alterações de substâncias químicas naturalmente presentes no corpo: serotonina e noradrenalina. No cérebro, essas duas substâncias químicas são associadas com a transmissão de pensamentos e sentimentos. No corpo, essas mesmas substâncias estão 
associadas com a regulação e a redução de sensações de dor. Quando essas substâncias químicas estão em desequilíbrio, o efeito pode ser sentido tanto no cérebro quanto no corpo. O paciente pode sentir tanto sintomas emocionais quanto sintomas físicos dolorosos associados à depressão. Para a melhora dos sintomas depressivos, emocionais e físicos, o médico pode prescrever um medicamento que aja sobre essas duas substâncias químicas vitais.

Nessa perspectiva, é "no cérebro" que o desequilíbrio químico acontece; o corpo é tratado como um Outro, apartado do cérebro, que sofre as conseqüências desse desequilíbrio. Um ponto marcante parece-me ser essa autonominação do cérebro em relação ao corpo; outro ponto central é a atenção dada aos sintomas físicos da depressão: no mesmo folheto, a foto de uma mulher, de costas, tocando a região do ombro e da nuca como se apontasse uma área na qual experimenta dor, é acompanhada de uma frase, entre aspas, na qual se lê: "Eu não tinha idéia de que minhas dores poderiam estar relacionadas à depressão". Ao que parece, dores com causa inespecífica têm sido associadas à depressão e consideradas como um possível sintoma, proposta que torna mais abrangente a possibilidade de diagnosticar a "doença". O cérebro, neste material, engloba ou subsume uma possível idéia de mente; os "sintomas emocionais dolorosos" também são entendidos em sua relação com o desequilíbrio químico, sendo este desequilíbrio a causa e aqueles sintomas, a conseqüência.

Esta leitura fisicalista da "depressão" é acompanhada por afirmações que situam a "doença" fora do campo moral, em um esforço explícito do texto dos folhetos nessa direção. Isto pode ser percebido em trechos que, ao situarem a "doença" em um cérebro que parece ter vida autônoma, desculpabilizam explicitamente o sujeito. Ainda no folheto do laboratório Lilly, lê-se:

Como eu cheguei a este ponto?

O paciente com depressão também se questiona sobre o motivo de estar sofrendo essas mudanças. Mas não é sua culpa. Acredita-se que a depressão seja uma condição médica causada por alterações de substâncias químicas no cérebro e por todo o corpo. Essas alterações podem ter sido desencadeadas por algum evento negativo em sua vida, por estresse excessivo ou até mesmo surgirem sem nenhuma causa aparente. De qualquer forma, a depressão é uma condição médica real, assim como as doenças cardiovasculares ou o colesterol alto e, portanto, é preciso ajuda especializada para sair dela.

Ainda que desencadeadas por "eventos negativos" ou "estresse excessivo", a "condição médica" da depressão é comparada a outros males cujos 
marcadores biológicos são tidos como fatos científicos. Em um parágrafo curto, atente-se, o termo "condição médica" é repetido duas vezes, com o reforço do adjetivo "real" na segunda vez. Por ser uma "condição médica", afirma-se que a depressão não é um mal de outra natureza, um oposto possível sendo o de condição psicológica, imagino; e o seu caráter "real" quer conferir algo de palpável a um estado que foge à possibilidade de medição por exames laboratoriais, como seria o caso, por exemplo, do nível de colesterol.

O texto deste folheto não é exceção, mas paradigmático do material publicitário dos laboratórios, tanto no que toca à localização da doença no cérebro, quanto à desculpabilização do indivíduo em relação à "doença". Em uma campanha de informes publicitários do Laboratório Wyeth, fabricante do antidepressivo Efexor, composta por anúncios de jornal, vemos mais uma vez essa tendência a negar um caráter moral para a depressão.

A depressão já é conhecida e suficientemente definida há muitos séculos, e em todas as culturas e países. Desse modo, não se pode encará-la como uma doença moderna, ou uma doença típica das grandes cidades.

Diagnosticar com precisão e tratar adequadamente um estado depressivo são procedimentos fundamentais para evitar riscos decorrentes da doença, e devolver ao paciente uma boa qualidade de vida [...] À volta de um paciente deve haver a compreensão de que a depressão não é preguiça, nem falta de caráter ou de vontade. Não adianta pedir ao paciente que reaja, pois ele precisa de medicamentos.

Em um primeiro momento, as peças publicitárias de divulgação às quais tive acesso chamavam a atenção por certa homogeneidade nas cores sempre claras: azul, branco, um verde suave - e pelos temas gráficos que, invariavelmente, traziam em algum ponto, quando não em destaque frontal, uma imagem da natureza, como campos de trigo, praias, um girassol, céu limpo e claro, um pássaro livre de sua gaiola; havia em algumas imagens pessoas sozinhas ou acompanhadas emolduradas por esses ambientes.

Se atentarmos aos temas gráficos de algumas peças publicitárias de diferentes laboratórios, tanto as fotos quanto as cores escolhidas fazem lembrar algo das indicações curativas que remetem ao contato com a "natureza". Na capa do folheto já comentado do laboratório Lilly, logo abaixo da chamada "Você sabe reconhecer os sintomas da depressão?", uma mulher por volta dos seus 30 anos, vestida com roupas brancas, aparece no meio de um campo de trigo com um rosto tranqüilo, parcialmente iluminado pelo sol. Um outro folheto, do laboratório Lundbeck - cuja logomarca, vale dizer, traz uma estrela-do-mar - com a chamada de capa "O que é depressão?", 
tem como tema gráfico um girassol. Ambas as peças apresentam uma linguagem voltada ao público leigo, informando sobre os sintomas da "doença" e a forma adequada de tratamento. Um anúncio, publicado na contracapa da revista Diálogo Médico, traz a chamada "Aguarde o novo antidepressivo da Roche" (que viria a ser o medicamento Ixel), e tem como tema gráfico uma gaivota estilizada.

Uma inversão interessante no uso de determinados valores pode ser percebida na capa de um CD promocional distribuído pelo laboratório Aché para divulgar o Somalium (bromazepam), um tranqüilizante da mesma linha do Valium, marca de grande sucesso nos anos 70, mas cujas vendas caíram devido a acusações de que causava dependência química. ${ }^{17}$ Nela pode ser lido: "O melhor da música New Age"; a ilustração mostra um pássaro voando, aparentemente um beija-flor, próximo a uma gaiola aberta, e o slogan "liberdade para viver".

Ao me deparar com o CD, lembrei-me de expressões como "jaula química", "prisão química" ou "gaiola química" para designar o efeito de medicamentos voltados para o sistema nervoso, visto que encobririam os verdadeiros sintomas. Neste caso, o efeito do medicamento é representado como libertador e não como um mecanismo de aprisionamento. O slogan criado para o Somalium e utilizado no CD promocional não é um caso isolado, mas representativo dos argumentos de venda de tranqüilizantes, antidepressivos e ansiolíticos. Paxil foi o primeiro remédio aprovado pelo FDA $^{18}$ para transtorno de ansiedade social em 1999; recentemente, um anúncio publicitário deste medicamento no New York Times Magazine trazia o slogan "Your life is waiting"; a chamada para o Paxil no site do laboratório GlaxoSmithKline mantém a mesma linha: "relieve the anxiety, reveal the person" (citado em Elliott 2003). Ainda que a publicidade de medicamentos vendidos somente sob prescrição médica seja controlada no Brasil, as campanhas informativas sobre as doenças, voltadas para o público leigo, são embasadas pelos mesmos valores.

Os temas gráficos comuns às peças publicitárias-informativas deixam no ar um paradoxo que acredito ser paralelo àquele expresso em textos sobre o uso de alguns medicamentos. Como essas imagens da "natureza", que traduzem uma idéia de "liberdade" e paz de espírito, encaixam-se com as teses fisicalistas a respeito das "doenças" ou dos sintomas que essas peças divulgam? Como poderíamos interpretar a convivência de textos que apontam ser a causa da depressão um desequilíbrio químico no cérebro e imagens que remetem ao meio ambiente harmonioso e equilibrado? Se os materiais publicitários analisados acima parecem coerentes com o paradigma cerebral de explicação da etiologia da depressão, as imagens nestes 
mesmos folhetos apontam para uma outra direção. Ali, vamos encontrar valores ligados à "natureza", uma categoria "crucial para a ordenação dos horizontes modernos" (Duarte 2005:158).

Ao que parece, a ambigüidade que pode ser aventada em um primeiro momento é apenas aparente. A linguagem técnica dos neurotransmissores, apesar de seu caráter aglutinador, ao ser passada ao público leigo, (e mesmo em peças de divulgação para médicos que estejam ligadas ao lazer — como no caso do CD de músicas New Age), não pode prescindir de valores estruturantes do pensamento ocidental, que aparecem de forma implícita no texto, mas explícita nas ilustrações. Nestas peças, o consumo de medicamentos para "depressão", "ansiedade" e os tranqüilizantes não são incompatíveis com a idéia de autonomia e criação de si, tampouco com a idéia de "natureza". Uma mensagem a qual poderíamos chamar fisicalista - em tom acusatório ou não - se faz acompanhar de valores ligados à subjetividade. Essa combinação peculiar reflete uma outra que está presente, de acordo com Nikolas Rose, na variante da noção de "pessoa", por ele denominada "neurochemical self". Referindo-se às drogas psiquiátricas, o autor afirma que "no interior da estruturação molecular destas drogas se imiscui uma ética, e as drogas elas mesmas personificam [embody] e incitam formas de vida específicas nas quais o 'eu real' é ao mesmo tempo 'natural' e está por ser produzido" (Rose 2003:59).

É possível constatar que aquilo que o medicamento é capaz de desvendar ao manipular os mecanismos de controle de humor pode ser representado como o "eu real", uma verdade que estava encoberta pelo mau funcionamento do corpo. Produz-se, por assim dizer, a "natureza" do ser, no sentido da sua verdade biológica, o pássaro que sai de sua gaiola e ganha liberdade. "Natureza" aqui, como explica Luna (2005:409), serve a uma dupla representação, sendo "tanto a biologia em si, como um referente do que é bom para continuar a existência, uma ordem moral representando um modelo ideal de realidade".

O binômio natureza/cultura é uma preocupação clássica do pensamento antropológico, e tem importância especial quando se discute o caráter social das intervenções químicas no corpo. A questão é que a idéia de "natural" não é sem ambigüidades e pode ser utilizada como argumento pelos dois lados de uma discussão. Um bom exemplo disto é o trabalho de Manica (2002) sobre a supressão da menstruação. Ela demonstra como argumentos a favor e contra a supressão fazem uso da categoria natureza, no primeiro caso, afirmando que as mulheres não menstruavam em um suposto "estado de natureza", estando sempre grávidas; no segundo, afirmando que a menstruação é parte de um ciclo natural. 
Parece-me correto, ao analisar o discurso do marketing biomédico, construir uma hierarquia entre fisicalismo e subjetividade, sendo o primeiro elemento "englobante". Temos então que, junto ao fisicalismo "englobante" de uma linguagem neuronal que explica as doenças em termos de um funcionamento inadequado do sistema de recaptação da serotonina ou de algum outro problema cerebral, corre uma dimensão moral subjetiva cujos valores muitas vezes parecem estar em oposição a tal fisicalismo. Numa dessas peças publicitárias afirma-se que o sujeito acometido por uma doença como a "depressão" nada tem a fazer, o que ele precisa é de medicamentos, não adianta pedir que ele reaja. Ao mesmo tempo, apela-se para valores como "vida", "natureza", "escolha", "autonomia" e "liberdade", encarnados em imagens de pessoas em situações de bem-estar em meio à "natureza" ou na de um pássaro livre da prisão de sua gaiola.

\section{Conclusão}

Segundo a OMS (2001), se continuar o crescimento atual na incidência da "depressão", a doença estará entre os principais problemas de saúde no Ocidente. Nos países desenvolvidos, os números atuais já apontam para uma "epidemia de larga escala"; mas o problema pode crescer ainda mais em países no eixo de uma modernidade periférica, como o Brasil. Ora, ainda que levemos a idéia de "epidemia" a sério — o tom de estranhamento fica por conta de não se tratar de doenças com transmissão viral ou bacteriológica - é interessante pensar como a biomedicina contemporânea chegou a esse "fato científico". Temos aqui um tema de pesquisa complexo, no qual se cruzam questões econômicas, éticas, ideológicas, políticas e de saúde. As perguntas que podem ser feitas se multiplicam: haveria recortes de gênero na incidência dos diagnósticos (os laboratórios informam que existe uma prevalência mais alta em mulheres) ou de faixa etária? Quais profissões seriam mais afetadas, visto que estes males podem se tornar as maiores causas de falta ao trabalho dentro de poucos anos?

Para responder a estas perguntas, creio que qualquer análise que tenda a "demonizar" um dos atores sociais em jogo pode cair em uma armadilha ingênua. Sim, os laboratórios farmacêuticos investem alto na divulgação de doenças (o chamado disease mongering); mas os valores que serão divulgados nas futuras campanhas publicitárias muitas vezes surgem de pesquisas com o público consumidor ou, de qualquer forma, fazem parte do arsenal simbólico do que denominamos a nossa "visão de mundo". É neste sentido que uma espécie de Neuro-weltanschauung constitui um fenômeno 
complexo. Como coloca Rose (2003:59), "se estamos experimentando uma reconfiguração neuroquímica da noção de 'pessoa', as implicações éticas e sociais para o século XXI serão profundas".

Como explicar a nossa suscetibilidade à idéia da cerebralização das vicissitudes da vida contemporânea? Mostrei aqui algumas das respostas que vêm sendo dadas a estas questões; tentei desenvolver também a hipótese de que, no material publicitário dos laboratórios farmacêuticos, a explicação fisicalista das doenças é acompanhada de imagens que remetem ao mundo subjetivo dos indivíduos, o que desvela o caráter físico-moral dessas condições. Valores como "autonomia", "escolha", "liberdade" e "natureza" são estruturantes de nossa visão de mundo no Ocidente e, por isso, podem servir a vários patrões. Esta idéia funciona aqui como uma hipótese explicativa da presença destes valores na publicidade de doenças e medicamentos para o sistema nervoso.

Recebido em 31 de janeiro de 2007

Aprovado em 23 de maio de 2007

Rogerio Lopes Azize é doutorando em Antropologia Social no PPGAS/Museu Nacional/UFRJ. E-mail: rogerioazize@yahoo.com.br; rogerioazize@hotmail.com

\section{Notas}

* Este texto foi produzido por apenas um cérebro, mas beneficiou-se do diálogo com muitos outros em diversos espaços de discussão. Não posso citar a todos aqui, então agradeço especialmente a Lilian Krakowski Chazan, Nicólas Viotti e ao professor Luiz Fernando Dias Duarte pelas sugestões de forma e conteúdo.

${ }^{1}$ A cada semana, novos exemplos, mais atuais, podem ilustrar o que é dito aqui. No programa Fantástico, da Rede Globo, de 26 de novembro de 2006, o cérebro, as sinapses e o funcionamento dos neurotransmissores são utilizados para se falar da depressão, com uma animação mostrando "o que causa a doença no cérebro". Na revista Veja, data de capa 28 de novembro de 2006, uma entrevista com um psiquiatra francês tem a depressão como tema; ele indica o consumo de Ômega 3 para o tratamento da depressão, afirma que a doença está sendo supermedicalizada, mas que o tratamento com antidepressivos é supervalorizado. Na mesma revista, de 6 de dezem- 
bro de 2006, a ilustração da capa é um cérebro, e sobre ele uma garrafa supostamente de bebida alcoólica; o tema da reportagem são os danos que o consumo de álcool na adolescência pode causar ao cérebro, afetando a memória e a aprendizagem.

${ }^{2}$ Tenho consciência de que essas categorias são abrangentes demais em termos de classificação, e que o termo "classes médias" serve como guarda-chuva para disposições diferenciadas de ethos (como se pode ver em Salem 1987), mais ou menos influenciado por uma "visão de mundo" fisicalista. Mas para este trabalho assumo o risco, visto que uma espécie de "linguagem cerebral" parece bastante difundida entre esses setores no meio urbano.

${ }^{3}$ A partir daqui, ISRS.

${ }^{4}$ Essa presença massiva do cérebro, de tecnologias de neuro-imagem e de avanços no campo da neurofarmacêutica vem sendo objeto de pesquisas sobre o papel da grande mídia na divulgação de novas tecnologias, como é o caso de Racine et alii 2006.

${ }^{5}$ Em uma situação não-formal de trabalho de campo, ouvi um relato a respeito da doença de uma pessoa conhecida, consumidora de antidepressivos, que afirmava saber exatamente o momento no qual ela teria adoecido: ao se deparar com o corpo do pai falecido, no velório, ela teria sentido uma "coisa na cabeça", uma "espécie de choque elétrico"; ao contar a história, ela imitava o som de um curto-circuito ou algo semelhante.

${ }^{6}$ Sobre esta questão, ver o trabalho de Cecília Chaves (2006), que fez um levantamento bastante completo sobre os grupos de relacionamento no Orkut voltados para depressão e os medicamentos a ela associados. Rose (2003:56) usa o termo biosocial groups para designar os grupos organizados em torno de doenças. Um dado interessante apontado por Moynihan e Cassels (2005) diz respeito a uma das estratégias de marketing dos laboratórios farmacêuticos: apoiar os grupos biossociais.

${ }^{7}$ A respeito da forma com que a idéia de "qualidade de vida" é utilizada na publicidade de laboratórios farmacêuticos, ver Azize $(2002,2006)$.

${ }^{8}$ Um dos campos que se ocupam de uma reflexão sobre as conseqüências do avanço da área das neurociências e da visualização do cérebro pelas novas tecnologias de imagem é a filosofia da consciência, que centra suas perguntas em torno da idéia de "identidade individual" e dos critérios de manutenção dessa identidade com o passar do tempo. Não se trata aqui de uma reflexão sobre esta área, para a qual não teria espaço ou competência, mas algumas idéias expressas neste texto têm inspiração em Ferret (1993) e Barbaras (2003).

${ }^{9}$ As novas tecnologias médicas e a noção de "pessoa" que as acompanham têm sido alvo de diversas pesquisas nos últimos anos, caso dos trabalhos de Chazan (2006) sobre as mais recentes tecnologias de visualização do feto, ou de Luna (2005) sobre as novas tecnologias reprodutivas, e ainda de Manica (2002) sobre a supressão da menstruação. 
${ }^{10}$ A relação entre a indústria farmacêutica, a divulgação de "doenças" e os médicos é um tema sobre o qual uma pesquisa com maior acuidade poderia ser feita. Não possuo dados de campo para ilustrar esta questão aqui; mas, sem dúvida, o acesso de vendedores de medicamentos (representantes comerciais dos laboratórios farmacêuticos) a médicos e a hospitais é uma questão controversa, devido ao óbvio interesse da indústria farmacêutica em divulgar seus produtos e à possível influência que este acesso possa ter sobre a política de prescrição dos profissionais.

${ }^{11}$ Neste texto, Parens propõe um debate muito mais refinado do que o feito aqui sobre o uso da categoria enhancement e a diferença entre enhancement, "tratamento" e "prevenção". Ele toca também em uma outra questão importante, mas que não será levantada neste artigo: a discussão sobre enhancement e políticas públicas de saúde; o limite entre o que seria uma intervenção como enhancement e uma outra, como "tratamento", que marcaria o que deve ser provido pelo Estado ou mesmo por planos privados de saúde.

${ }^{12}$ Ao que parece, o primeiro a se fazer esta pergunta foi Peter Kramer, no livro Listening to Prozac, de 1993. Os textos que serão citados a seguir, em sua grande maioria, fazem referência a Kramer.

${ }^{13}$ Tradição que ele circunscreve à cultura americana, mas poderíamos afirmar que hoje atravessa o Ocidente como um valor importante.

${ }^{14}$ No livro Admirável Mundo Novo, de Aldous Huxley (2001[1932]), um clássico das anti-utopias de ficção científica, o Soma é um comprimido ingerido regularmente pelas pessoas com o objetivo de gerar um estado de homeostase, evitar conflitos e jogar uma bruma entre o indivíduo e o mundo exterior, como se percebe no trecho a seguir: "uma segunda dose de soma [...] erguera um mundo intransponível entre o universo real e seus espíritos" (2001:95).

${ }^{15}$ Maluf (2002), em um texto sobre gênero e corporalidade, ao analisar a fala da personagem Agrado, no filme Tudo sobre minha mãe, de Pedro Almodóvar, que diz no palco ser mais autêntica do que a sua audiência por ter feito escolhas e redesenhado o seu corpo fazendo uso de silicone. Para a personagem travesti do filme, a sua "natureza" e verdade íntima, o "autêntico" em si é o produto de sua intervenção sobre o próprio corpo, resultado mais verdadeiro do que o destino biológico ao qual ela não se quer ver presa. Traço aqui um paralelo entre este tipo de argumento e a defesa de DeGrazia da possibilidade de criação de si, ainda que fazendo uso de meios químicos para isso.

${ }^{16}$ Ver, por exemplo, Moynihan e Cassels (2005). Os autores fazem um esforço de denúncia das técnicas de marketing da indústria farmacêutica, referindo-se a uma entrevista dada por um executivo do Laboratório Merck à revista Fortune, "há 30 anos atrás" (1975?), na qual ele afirma seu desagrado a respeito da limitação dos consumidores da Merck às pessoas doentes. O seu sonho seria um momento no qual o laboratório começasse a criar medicamentos para pessoas saudáveis. Para Moynihan e Cassels, esse tempo já chegou: as novas estratégias da indústria estariam focadas 
em campanhas ambíguas de awareness-raising, visando informar a população a respeito de determinada doença ou transtorno - o problema é que tais campanhas seriam publicidade de medicamentos travestida de esforço para informar a população a respeito de uma doença pouco conhecida e da existência de um tratamento. Sem meias palavras, o livro mostra que existem profissionais de marketing especializados em criar doenças, uma forma sofisticada de vender medicamentos. Moynihan foi também um dos editores de um dossiê especial da revista PlosMedicine sobre o chamado disease mongering.

${ }^{17} \mathrm{O}$ CD não tem referência ao ano em que foi prensado ou distribuído. Não possuo dados atuais sobre as vendas de Somalium.

${ }^{18}$ FDA é a sigla para Food and Drug Administration, o órgão do governo dos EUA responsável por regular questões ligadas a medicamentos.

\section{Referências bibliográficas}

ANDREASEN, Nancy C. 2005. Admirável cérebro novo: vencendo a doença mental na era do genoma. Porto Alegre: Artmed.

APPLBAUM, Kalman. 2006. "Pharmaceutical marketing and the invention of the medical consumer". PLoS Med, $3(4): 189$

AZIZE, Rogerio Lopes. 2002. A química da qualidade de vida: um olhar antropológico sobre uso de medicamentos e saúde em classes médias urbanas. Dissertação de mestrado. Universidade Federal de Santa Catarina. 121p. . 2006. "Saúde e estilo de vida: divulgação e consumo de medicamentos em classes médias urbanas". In: D. K. Leitão et alii (orgs.), Antropologia e consumo: diálogos entre Brasil e Argentina. Porto Alegre: Editora AGE. pp.119-137.

BARBARAS, Renaud. 2003. "A alma e o cérebro". In: A. Novaes (org.), O homemmáquina: a ciência manipula o corpo. São Paulo: Cia. das Letras. pp.65-76.
BEZERRA JR., Benilton. 2000. "Naturalismo como anti-reducionismo: notas sobre cérebro, mente e subjetividade". Cadernos IPUB, VI:158-177.

CAIRUS, Henrique. 1999. "Da natureza do homem. Corpus hippocraticum". História, Ciências, Saúde: Manguinhos, VI:395-430.

CARDOSO, Marina. 2002. "Psiquiatria e Antropologia: notas sobre um debate inconcluso". Ilha: Revista de Antropologia, 4(1):85-113.

CHAVES, Cecília Maria Silveira. 2006. "Antidepressivos: questões para pensar o consumo". Anais da 25 $5^{a}$ Reunião Brasileira de Antropologia, Goiânia.

CHAZAN, Lilian Krakowski. 2006. "Fotógrafo de interiores: o consumo de imagens fetais e a construção do prazer de ver". In: D. K. Leitão et alii (orgs.), Antropologia e consumo: diálogos entre Brasil e Argentina. Porto Alegre: Editora AGE. pp.101-118.

CORNWELL, John. 2004. "The Prozac story". In: D. Rees \& S. Rose (orgs.), 
The new brain sciences. Perils and prospects. Cambridge: Cambridge University Press. pp. 223-231.

DeGAZIA, David. 2004. "Prozac, enhancement and self-creation". In: Carl Elliott \& Tod Chambers. Prozac as a way of life. Chapell Hill \& London: University of North Carolina Press. pp. 33-47.

DUARTE, Luiz Fernando D. 1986. Da vida nervosa nas classes trabalhadoras urbanas. Rio de Janeiro: Jorge Zahar Editor.

1994. "A outra saúde: mental, psicossocial, físico-moral?". In: P. C. Alves \& M. C. Minayo (orgs.), Saúde e Doença - um olhar antropológico. Rio de Janeiro: Editora Fiocruz. pp. 79-97.

. 2003. "Indivíduo e pessoa na experiência da saúde e da doença". Ciência e Saúde Coletiva, 8(1):173183.

2005. "Ethos privado e justificação religiosa. Negociações da reprodução na sociedade brasileira". In: M. L. Heilborn et alii (orgs.), Sexualidade, família e ethos religioso. Rio de Janeiro: Garamond. pp. 137-176.

DUMIT, Joseph. 2004. Picturing personhood: brain scans and biomedical identity. Princeton and Oxford: Princeton University Press.

EHRENBERG, Alain. 2004. "Le sujet cerebral". Esprit, 309:130-155.

ELLIOTT, Carl. 2003. Better than well: american medicine meets the american dream. New York: W. W. Norton \& Company.

2004. "Introduction: Prozac as a way of life". In: Carl Elliott \& Tod Chambers. Prozac as a way of life. Chapell Hill \& London: University of North Carolina Press. pp. 1-18.

FERRET, Stephane. 1993. Le philosophe et son scalpel: le problème de l'identité personnelle. Paris: Minuit.
FOUCAULT, Michel. 1977. História da Sexualidade I: a vontade de saber. Rio de Janeiro: Edições Graal.

JUENGST, Eric T. 1998. "What does enhancement mean?" In: E. Parens. Enhancing human traits: ethical and social implications. Washigton, D.C.: Georgetown University Press. pp. 29-47.

HEALY, David. 2004. "Psychopharmacology at the interface between the market and the new biology". In: S. Rose \& D. Rees (orgs.), The new brain sciences: perils and prospects. New York: Cambridge University Press. pp. 232-248.

HUXLEY, Aldous. 2001. Admirável mundo novo. São Paulo: Globo.

KRAMER, Peter D. 1994. Ouvindo o Prozac: uma abordagem profunda e esclarecedora sobre a "pílula da felicidade". Rio de Janeiro: Record.

LATOUR, Bruno \& WOOLGAR, Steve. 1997. A vida de laboratório: a produção dos fatos científicos. Rio de Janeiro: Relume Dumará.

LATOUR, Bruno. 2000. Ciência em ação: como seguir cientistas e engenheiros sociedade afora. São Paulo: Editora UNESP.

LE BRETON, David. 2003. Adeus ao corpo: antropologia e sociedade. Campinas: Papirus.

LUNA, Naara. 2005. "Natureza humana criada em laboratório: biologização e genetização do parentesco nas novas tecnologias reprodutivas". História, Ciências, Saúde - Manguinhos, 12(2):395-417.

MALUF, Sônia Weidner. 2002. "Corporalidade e desejo: tudo sobre minha mãe e o gênero na margem". Revista Estudos Feministas, 1:143-153.

MANICA, Daniela Tonelli. 2002. "Supressão da menstruação: uma discussão sobre alguns dos embates entre natural e cultural". Anais da $26^{a}$ Reunião da ANPOCS, Caxambu. 
MOYNIHAN, Ray \& CASSELS, Alan. 2005. Selling sickness: how the world's biggest pharmaceutical companies are turning us all into patients. New York: Nation Books.

MOYNIHAN, Ray. \& HENRY, David. 2006. "The fight against disease mongering: generating knowledge for action". PLoS Med, 3(4):191.

OMS. Relatório sobre a Saúde no Mundo. 2001. Organização Panamericana da Saúde - Organização Mundial de Saúde - ONU. World Health Organization, Genebra, Suiça. (transcrição de partes do relatório disponível em www. psiqweb.med.br/acad/oms1.html ).

PARENS, Erik. 1998. "Is better always good? The enhancement project". In: E. Parens (org.), Enhancing human traits: ethical and social implications. Washington: Georgetown University Press. pp.1-28.

PIGNARRE, Philippe. 1999. O que é o medicamento? Um objeto estranho entre ciência, mercado e sociedade. São Paulo: Editora 34.

PORTER, Roy. 2004. Das tripas coração: uma breve história da medicina. Rio de Janeiro: Record.

RABINOW, Paul. 1999. Antropologia da razão. Rio de Janeiro: RelumeDumará.

RACINE, Eric; BAR-ILAN, Ofek \& ILLES, Judy. 2006. "Brain Imaging: a decade of coverage in the print midia". Science communication, 28(1):122143 (disponível em http://scx.sagepub.com).

ROSE, Nikolas. 2003. "Neurochemical selves". Society, 41(1):46-59. . 2007. The politics of life itself: biomedicine, power, and subjectivity in the twenty-first century. Princenton \& Oxford: Princeton University Press.

RUSSO, Jane A. \& PONCIANO, Edna T. 2002. "O sujeito da neurociência: da naturalização do homem ao re-encantamento do mundo". Physis: revista de saúde coletiva, 12(2):345-373.

SALEM, Tânia. 1986. "Família em camadas médias: uma perspectiva antropológica". Boletim Informativo e Bibliográfico de Ciências Sociais, 21:25-39.

SENNETT, Richard. 2005. A corrosão do caráter: conseqüências pessoais do trabalho no novo capitalismo. Rio de Janeiro: Record.

SIMMEL, Georg. 2005 [1903]. "As grandes cidades e a vida do espírito". Mana. Estudos de Antropologia Social, 11(2):577-591

VIDAL, Fernando. 2005. "Le sujet cérébral: une esquisse historique et conceptuelle". Psychiatrie, sciences humaines, neurosciences, 3(11): 37-48. 
Resumo

Entre os órgãos do corpo humano, o cérebro é tido hoje como aquele que define a nossa identidade pessoal. Uma "linguagem da serotonina" é utilizada para explicar sintomas dos mais diversos, entre eles, estados de humor como a "depressão" e a "ansiedade", linguagem esta que entrou para o discurso cotidiano do público leigo. A literatura aponta para o surgimento de um "sujeito cerebral" na contemporaneidade, marcado por um borrar das fronteiras entre mente e cérebro. Todos os anos, laboratórios farmacêuticos investem milhões de dólares para divulgar medicamentos voltados para o tratamento das chamadas desordens mentais-cerebrais. Parte desse investimento é voltada não para a divulgação dos produtos, mas sim para a das doenças elas mesmas. Trata-se aqui de refletir sobre a noção de "pessoa" que esse material veicula, na qual o paradigma "sujeito cerebral" caminha lado a lado de uma imagética físico-moral.

Palavras-chave: Cérebro, Medicamentos, Depressão e Ansiedade, Enhancement, "Pessoa", Saúde/Doença

\section{Abstract}

Of all the organs of the human body, the brain is taken today as the one that defines our personal identity. A 'serotonin language' is used to explain a wide range of symptoms, including moods such as 'depression' and 'anxiety,' and has now become part of everyday discourse. The literature indicates the contemporary emergence of a 'cerebral subject' where the frontiers between mind and brain become blurred. Every year, pharmaceutical labs invest millions of dollars in marketing drugs designed to treat so-called mental-cerebral disorders. Part of this investment is focused not on marketing the products but the diseases themselves. The aim of this article is to examine the notion of 'person' contained in this material, where the 'cerebral subject' paradigm goes hand-in-hand with physico-moral imagery.

Key words: Brain, Drugs, Depression and Anxiety, Enhancement, 'Person,' Health/Disease 